\title{
Temporal Evolution of Disc in Young Patients with Low Back Pain and Stress Reaction in Lumbar Vertebrae
}

\author{
(D) A. Sharma, ${ }^{\text {K }}$. Sargar, and (D) A. Salter
}

\begin{abstract}
BACKGROUND AND PURPOSE: Although stress-induced bony changes often resolve with conservative treatment, the long-term effects of such mechanical stresses on intervertebral discs have not been studied. We aimed to assess the differences in the temporal evolution of disc in segments of the lumbar spine with and without signs of increased mechanical stresses.
\end{abstract}

MATERIALS AND METHODS: Using MR imaging performed $>6$ months apart, 2 radiologists evaluated lumbar intervertebral discs for degenerative changes affecting the annulus fibrosus, the nucleus pulposus, and the endplates in 42 patients ( 22 male, 20 female; mean age, $16.0 \pm 3.7$ years [range, 7-25 years]) with low back pain and imaging evidence of stress reaction/fracture in the lumbar spine. Data were analyzed for differences in the presence and progression of disc degeneration in stressed versus nonstressed segments.

RESULTS: At baseline, stressed discs had a higher burden of annular fissures, radial fissures, herniation, and nuclear degeneration. Endplate defect burden was comparable in stressed and control discs. At follow-up, the burden of new annular fissures and endplate defects was comparable for stressed and control discs. However, a higher proportion of stressed discs showed worsening nuclear signal intensity grade (14.3\% versus $0 \%$ control discs; $P=.008)$ and worsening nuclear degeneration grade $(11.9 \%$ versus $0 \%$ control discs; $P=.02)$. An increased risk of progressive nuclear degeneration of stressed discs was observed irrespective of the outcome of bony changes.

CONCLUSIONS: Stressed discs exhibit a higher burden of nuclear and annular degeneration at baseline. These discs have a higher risk of progressive nuclear degeneration irrespective of improvement or worsening of stress-related bony changes.

S tress reaction in posterior elements of the lumbar spine is a common cause for low back pain in young athletes. ${ }^{1-11}$ Whereas ongoing mechanical stresses can cause overt stress fractures and eventually spondylolisthesis, an initial microtrabecular bony injury within an affected pedicle or pars interarticularis manifests either as edema on MR imaging or as increased uptake on a bone scan..$^{2-5,12,13}$ Intervertebral discs attached to stressed vertebrae experience higher mechanical stresses, and even at a young age, these stressed discs demonstrate a higher burden of annular fissures, herniation, and loss of normal hyperintensity of the nucleus pulposus on T2WI. ${ }^{14}$ The stressed bone often heals with conservative management, allowing patients to resume their

Received February 8, 2017; accepted after revision March 17.

From the Mallinckrodt Institute of Radiology (A. Sharma, K.S.) and Department of Biostatistics (A. Salter), Washington University School of Medicine, St. Louis, Missouri; Department of Radiology (A. Sharma), Barnes-Jewish Hospital South, St. Louis, Missouri; and Department of Radiology (A. Sharma), St. Louis Children's Hospital, St. Louis, Missouri.

Please address correspondence to Aseem Sharma, MD, Mallinckrodt Institute of Radiology, Washington University School of Medicine, Campus Box 8131, $510 \mathrm{~S}$.

Kingshighway Blvd, St. Louis, MO 63110; e-mail: sharmaa@mir.wustl.edu

http://dx.doi.org/10.3174/ajnr.A5237 athletic activities. ${ }^{12,15,16}$ In contrast to the ability of bone to heal itself, there is little evidence to support disc regeneration after the initiation of the degenerative cascade, wherein an insult to the disc may initiate a chain of chemical or inflammatory events that can further damage the disc. ${ }^{17}$ Although cross-sectional studies have highlighted a higher prevalence of disc degeneration in patients with spondylolysis and spondylolisthesis in adults, ${ }^{18-21}$ there is a paucity of information about the risk of progressive disc degeneration in young patients presenting with clinical and imaging evidence for bony stresses in the lumbar spine. We aimed to study the longitudinal evolution of degeneration in the individual components of stressed discs, hypothesizing that the stressed discs would demonstrate a higher burden of progressive degeneration relative to control discs.

\section{MATERIALS AND METHODS}

Our institutional review board at Washington University School of Medicine approved this retrospective longitudinal observational study, waiving the need for consent.

\section{Patient Selection}

We identified consecutive patients diagnosed with a stress reaction or fracture in the posterior elements of the lumbar spine over 
an 8-year period ending in 2015. Inclusion criteria were age $<25$ years and the availability of lumbar spine MR images obtained first at presentation and then $>6$ months later. All patients presented with low back pain without any history of acute injury. Diagnosis was confirmed by the senior author, a board-certified neuroradiologist with $>15$ years of experience. Patients with spinal infection and neoplasms were excluded. Forty-two patients (22 male, 20 female; mean age, $16.0 \pm 3.7$ years [range, 7-25 years]) were included. Bony stresses involved the L5 segment in 29 (69.0\%) patients and the L4 segment in 9 (21.4\%). Four patients (9.6\%) had bony stresses at 2 segments (L3 and L4 in 2; L4 and L5 in 2). Thirty-nine of 46 (84.8\%) stressed segments showed bilateral changes. Anterolisthesis (grade 1 in all) was present in 15 (35.7\%) cases. The mean duration between 2 studies was 19.8 months (range, 6-51 months). On the Hollenberg grading system, ${ }^{2}$ which categorizes stress injury into grades 1 through 4 (corresponding to edema without fracture line, incomplete fracture, complete fracture with edema, and fracture nonunion without associated edema, respectively), 18 of 42 (42.9\%) patients were graded 1 or 2 , indicating a lack of complete fracture.

\section{Imaging Analysis}

MR imaging was performed on $1.5 \mathrm{~T}$ or $3 \mathrm{~T}$ scanners (Sonata, Vision, Avanto, Magnetom Aera, and Trio; Siemens, Erlangen, Germany) and included sagittal T1WI (TR, 448-640 ms; TE, 11-29 ms; thickness, $3 \mathrm{~mm}$ ), sagittal T2WI (TR, 3110-5390 ms; TE, 99-164 ms; thickness, $3 \mathrm{~mm}$ ), sagittal STIR (TR, 4300-6359 ms; TE, 18-100 ms; TI, 135-160 ms; thickness, 3 $\mathrm{mm}$ ), and axial T2WI (TR, 2280-4820 ms; TE, 102-120 ms; thickness, 3-4 $\mathrm{mm})$.

Two radiologists (K.S., a neuroradiology fellow, and A. Sharma, the senior author) evaluated MR images in a consensus read. Each component of the intervertebral discs between the T12 and S1 segments was evaluated on baseline scans as reported previously. ${ }^{22}$ The annulus fibrosus was assessed for annular fissure, radial fissure (annular fissure with its hyperintensity in continuity with that of the nucleus pulposus), and herniation. The nucleus pulposus was graded according to the Pfirrmann classification $^{23}$ and on a 6-point signal intensity-based scale. ${ }^{24}$ The presence or absence of endplate defects was noted. The reliability of these scales had been tested earlier and was reported to range from moderate to almost perfect $(\kappa=0.57-$ 0.86). ${ }^{24,25}$ To assess the longitudinal temporal evolution of disc degeneration and bony changes, the initial and follow-up scans were viewed simultaneously.

\section{Stressed Discs and Control Discs}

Both intervertebral discs adjacent to the stressed bony segments were considered stressed (Table 1). The lumbar spine was divided into cranial (T12 through L3) and caudal (L3 through S1) segments. To account for the effects of axial loading, control discs were chosen from the same (cranial or caudal) segment to which the stressed discs belonged (Table 1$).{ }^{14}$

\section{Statistical Analysis}

For the initial scan, the burden of individual degenerative changes was calculated on a per-disc basis. ${ }^{14}$ For example, if 1 of the 2
Table 1: Definitions of stressed discs and control discs for each vertebral segment showing bony stress

\begin{tabular}{lll}
\hline $\begin{array}{c}\text { Location of Bony } \\
\text { Stress Changes }\end{array}$ & \multicolumn{1}{c}{$\begin{array}{c}\text { Stressed } \\
\text { Discs }\end{array}$} & \multicolumn{1}{c}{ Control Discs } \\
\hline T12 & T12-LI & L1-2, L2-3 \\
L1 & T12-L1, L1-2 & L2-3 \\
L2 & L1-2, L2-3 & T12-L1 \\
L3 & L2-3, L3-4 & T12-L1, L1-2, L4-5, L5-S1 \\
L4 & L3-4, L4-5 & L5-S1 \\
L5 & L4-5, L5-S1 & L3-4 \\
S1 & L5-S1 & L3-4, L4-5 \\
\hline
\end{tabular}

stressed discs demonstrated annular fissure, the burden of annular fissures in stressed discs was 0.5. Similarly, if the only control disc had nuclear degeneration, the burden of nuclear degeneration for the control disc was 1 . For meeting the binary definition of nuclear degeneration, the disc had to be graded III or higher on the Pfirrmann scale. The baseline degenerative burden in stressed and control discs was compared. Differences between stressed and control discs for various parameters were assessed by using a nonparametric paired test, the Wilcoxon signed rank test, and the $\mathrm{McNemar}$ test. Correlation was sought between baseline disc degeneration, the presence of spondylolisthesis, and the grade of bony stress. Differences between scans were used to assess the burden of new degeneration by using similar tests. In cases where no new changes were observed in the discs of all patients, a binomial test of proportions was calculated. The Fisher exact test was used to test differences between patients with persistent bony stresses and those with improvement. A $P$-value $<.05$ was considered significant. All tests were 2-sided.

\section{RESULTS}

At baseline, the burdens of annular fissures, radial fissures, and herniation were higher in stressed discs compared with control discs $(P<.0001, P<.0001$, and $P=.024$, respectively) (Table 2; Fig 1). Median [25th, 75th percentiles] signal intensity rating for stressed discs was $1.39[1,2]$, significantly higher than control discs $(1[1,1] ; P<.0001$ [Table 2]). A higher percentage (52.4\%) of patients showed at least 1 stressed disc with signal intensity grade $>1$ compared with those with a similar change in control discs $(11.9 \%$; $P<.0001)$. Although the mean Pfirrmann grade in the 2 groups was comparable, a higher percentage of patients had nuclear degeneration (Pfirrmann grade $>$ II) in stressed segments $(19.1 \%$ versus $4.8 \%$ for control segments; $P=.031)$. The endplate defect burden in stressed and control discs was comparable (Table 2).

No significant Spearman correlation was observed between various parameters of disc degeneration in stressed discs and spondylolisthesis at baseline. No significant Spearman correlation was present between annular fissure or radial fissure burdens in stressed discs and bony stress reaction grade (Wilcoxon signed rank, $P=.37$ and $P=.29$ ). However, there was a significant difference in the median stress grade for stressed discs showing nuclear degeneration compared with those without such indications (Wilcoxon signed rank, $P=.034$ ). For control discs, none of the parameters demonstrated any correlation with the grade of bony stress reaction.

At follow-up, the burdens of new annular fissures, new radial 
Table 2: Disc degeneration in stressed and nonstressed segments of lumbar spine

\begin{tabular}{lccccc}
\hline & \multicolumn{2}{c}{ Baseline Degeneration } & & \multicolumn{2}{c}{ Progressive Degeneration } \\
\cline { 2 - 3 } \cline { 5 - 6 } & Stressed Discs & Control Discs & & Stressed Discs & Control Discs \\
\hline Annular fissure $^{\mathrm{a}, \mathrm{b}}$ & $0.76 \pm 0.35$ & $0.37 \pm 0.48$ & & $0.07 \pm 0.18$ & $0.05 \pm 0.22$ \\
& $37(88.1)$ & $16(38.1)$ & & $6(14.3)$ & $2(4.9)$ \\
Radial fissure $^{\mathrm{a}, \mathrm{b}}$ & $0.59 \pm 0.43$ & $0.17 \pm 0.38$ & & $0.07 \pm 0.18$ & $0.05 \pm 0.22$ \\
& $30(71.4)$ & $8(19.1)$ & & $6(14.3)$ & $2(4.9)$ \\
Herniation $^{\mathrm{a}, \mathrm{b}}$ & $0.07 \pm 0.20$ & $0.00 \pm 0.00$ & & $0.01 \pm 0.08$ & $0.00 \pm 0.00$ \\
& $5(11.9)$ & $0(0.0)$ & & $1(2.4)$ & $0(0.0)$ \\
Nuclear degeneration $^{\mathrm{a}, \mathrm{b}, \mathrm{b}}$ & $0.13 \pm 0.30$ & $0.05 \pm 0.22$ & & $0.10 \pm 0.28$ & $0.00 \pm 0.00$ \\
& $8(19.1)$ & $2(4.8)$ & & $5(11.9)$ & $0(0.0)$ \\
Nuclear SI loss $^{\mathrm{a}, \mathrm{b}, \mathrm{d}}$ & $0.39 \pm 0.42$ & $0.12 \pm 0.33$ & & $0.17 \pm 0.48$ & $0.00 \pm 0.00$ \\
& $22(52.4)$ & $5(11.9)$ & & $6(14.3)$ & $0(0.0)$ \\
EPD $^{\mathrm{a}, \mathrm{b}}$ & $0.11 \pm 0.24$ & $0.12 \pm 0.33$ & & $0.00 \pm 0.00$ & $0.00 \pm 0.00$ \\
& $8(19.1)$ & $5(11.9)$ & & $0(0.0)$ & $0(0.0)$ \\
\hline
\end{tabular}

Note:-EPD indicates endplate burden; SI, signal intensity.

a Burden (mean \pm SD) of degenerative parameter calculated on per disc basis.

${ }^{b}$ Number (\%) of patients with specified degenerative parameters in stressed or control segments of lumbar spine; "Baseline Degeneration" refers to changes on MR scan obtained at the time of presentation and "Progressive Degeneration" refers to appearance of new changes noted on a follow-up MR scan obtained $>6$ months later.

'Defined as discs graded higher than 2 on Pfirrmann grading system.

${ }^{\mathrm{d}}$ Discs graded higher than 1 on a 6-point scale based on SI on T2-weighted images indicating any loss of normal hyperintense signal.

\section{Burden of Baseline Degeneration}

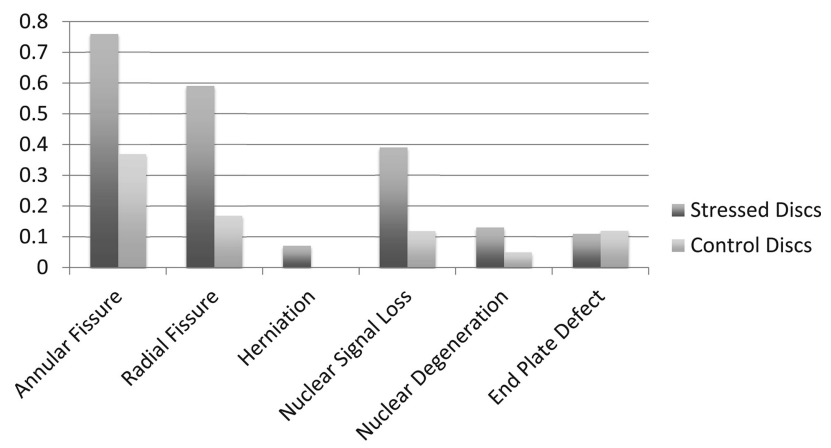

FIG 1. A bar diagram demonstrating the baseline burden of degenerative parameters in the individual components of the lumbar intervertebral discs of patients $<25$ years old and presenting with low back pain caused by stress reaction in the posterior elements of the lumbar vertebrae. Stressed discs refer to intervertebral discs attached to the vertebra with increased bony stresses. Control discs refer to discs not in contact with stressed vertebra, but with otherwise equivalent axial loading.

\section{Burden of Progressive Degeneration}

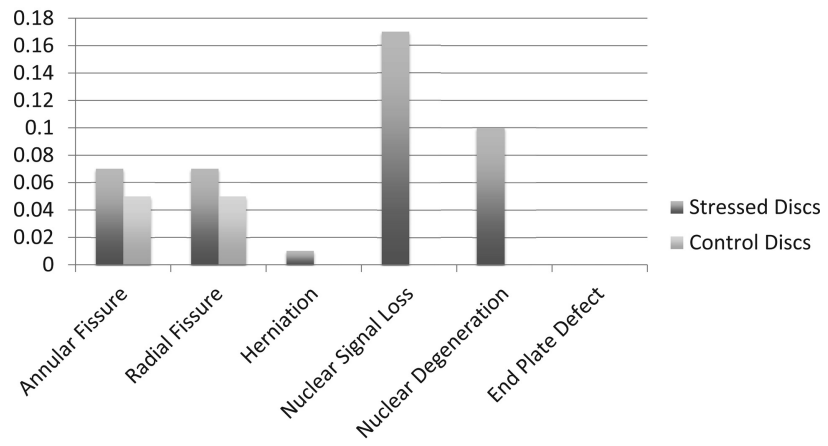

FIG 2. A bar diagram demonstrating the burden of new degenerative changes in stressed and control discs as observed on follow-up MR imaging acquired $>6$ months after the baseline scan. fissures, and new herniation in stressed $\operatorname{discs}(0.06 \pm 0.17,0.07 \pm 0.18$, and $0.01 \pm 0.08$, respectively; Table 2 ; Fig 2$)$ and control discs $(0.05 \pm 0.22,0.05 \pm$ 0.22 , and $0.00 \pm 0.00$, respectively; Table 2; Fig 2) were not significantly different. Similarly, the percentages of stressed and control discs demonstrating new annular fissure, radial fissure, or herniation were also comparable $(P=$ $.375, P=.219$, and not available). Worsened signal intensity and Pfirrmann grade were present in $6(14.3 \%)$ and 5 (11.9\%) stressed discs, respectively (Figs 3-5). Control discs had no shift in their signal intensity or Pfirrmann rating. The binomial test of proportions indicates that stressed discs had a statistically different proportion with signal intensity $(P=.008)$ and Pfirrmann rating $(P=$ .017). No new endplate defects were found for either stressed or control discs (Table 2; Fig 2).

Fisher exact test did not reveal any differences in the parameters of progressive disc degeneration in patients with improved ( 8 patients; Fig 5) and those with persistent/worsening bony stress reaction (34 patients) on follow-up imaging.

\section{DISCUSSION}

Previous studies have reported a high prevalence of disc degeneration in adults with spondylolysis, with or without spondylolisthesis. ${ }^{18-20}$ Degeneration of discs at the level of spondylolisthesis has been documented in adolescents. ${ }^{21,26}$ It has also been demonstrated that early degenerative changes in the form of annular fissures, radial fissures, and nuclear degeneration can be seen around stressed vertebral segments in young patients with a stress reaction detected on MR imaging before complete stress fracture. ${ }^{14}$ By showing a relatively higher overall rate of worsened disc degeneration in stressed discs in follow-up studies, our results demonstrate, for the first time, the progressive nature of degenerative changes initiated in association with bony stress reaction/ fractures at a young age. ${ }^{14}$

Although disc degeneration progresses relatively slowly, the long life expectancy of patients included in our study makes these results particularly noteworthy. It should be noted that most outcome studies in this patient population are limited to 1-3 years of follow-up, a rather short time span compared with the life expectancy of these patients. ${ }^{8,27,28}$ Based on the progressive disc degeneration seen in our study, it is likely that the advanced disc degeneration documented in many adults with spondylolytic spondylolysthesis ${ }^{18,19}$ reflects the sequela of a mechanical process that initiated degenerative cascade in discs at the same time it induced stress fractures in the vertebral elements.

Outcome studies in young patients with back pain caused by stress reaction have focused on either clinical symptoms or the evolution of stressed bone, with relatively few studies exploring the effects of such stresses on associated intervertebral 


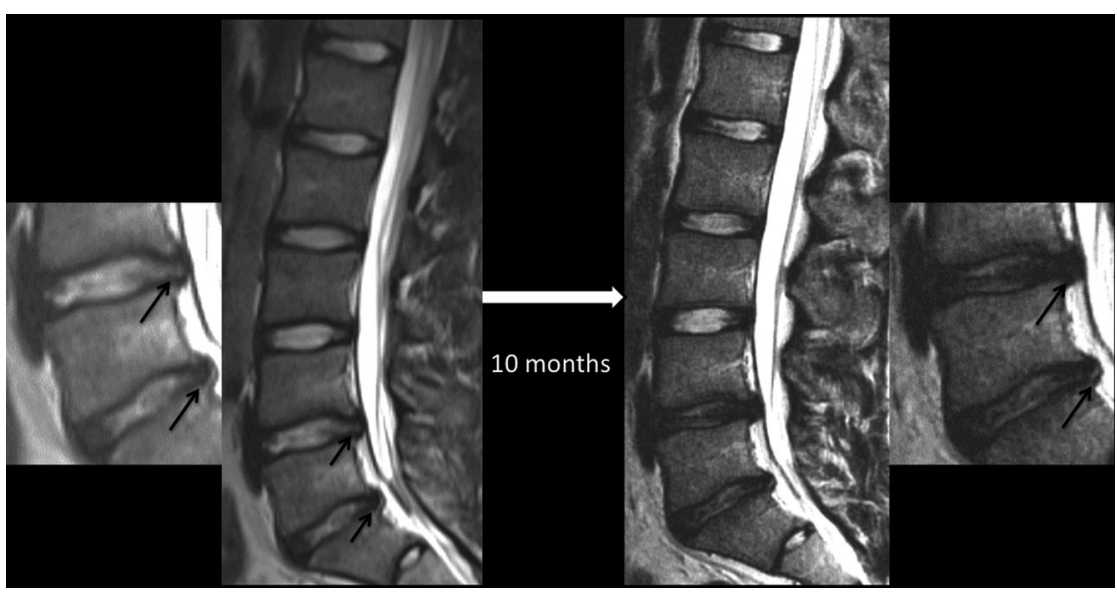

FIG 3. Sequential MR images of the lumbar spine showing the evolution of lumbar disc degeneration in a 16-year-old female patient presenting with low back pain and evidence for stress reaction in both $L 5$ pedicles (not shown) at the time of presentation. Both intervertebral discs (L4-5 and L5-S1; also shown in magnified images) around the stressed segment demonstrated the presence of annular fissures (arrows), disc herniation, and nuclear degeneration at baseline. The control disc in the lower half of the lumbar spine (L3-4) had an intact annulus and preserved nuclear signal intensity at baseline. Follow-up MR imaging 10 months later reveals stability in the appearance of the control disc, but interval loss of signal intensity, signifying progressive nuclear degeneration of both stressed discs. The annular fissure at the L4-5 level has become less conspicuous, but one at the L5-S1 level is more easily recognizable on a follow-up scan.

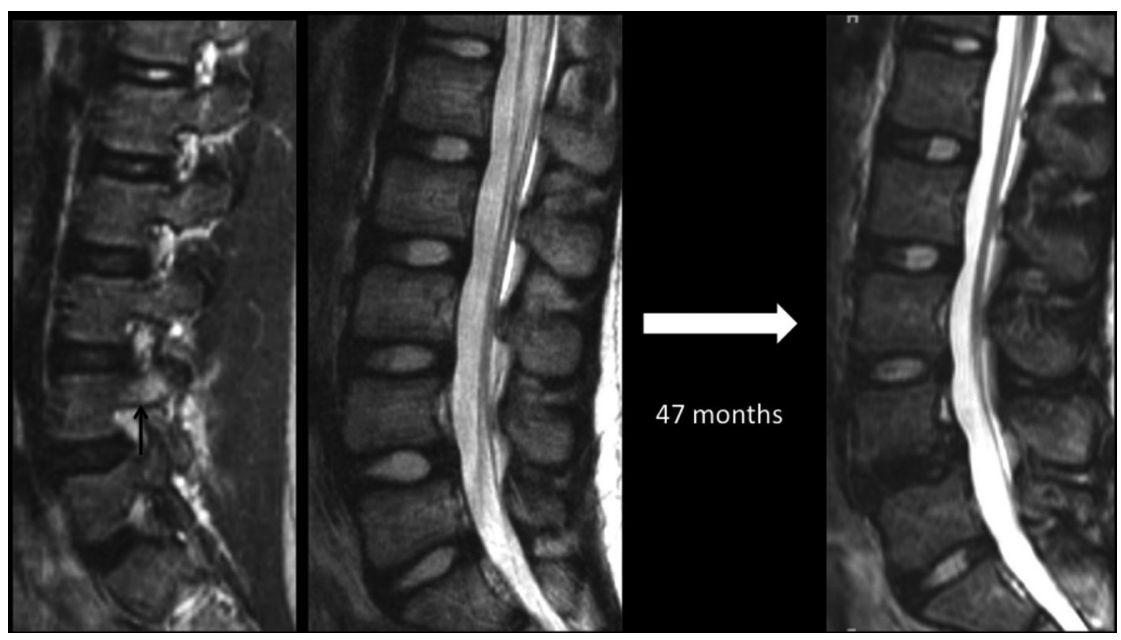

FIG 4. Sequential lumbar MR imaging over a 47-month period in a 12 -year-old female patient presenting with low back pain caused by a partial L4 stress fracture as indicated by edema in the right pedicle (arrow) on a parasagittal STIR image. Initial and follow-up midsagittal T2weighted images highlight marked progressive nuclear degeneration in the inferior stressed disc at the L4 -5 level, but preserved appearance of a more caudally located control disc at the L5-S1 level.

discs around the time of presentation. ${ }^{8,12,15,27,29,30}$ Conservative treatment is often successful in alleviating patients' symptoms, allowing a high proportion of these patients to resume the offending physical activity. Follow-up imaging in our patients was done based on clinical need, and thus, our study fails to document the evolution of disc degeneration in patients who become asymptomatic. However, given the propensity of disc degeneration to remain asymptomatic and a higher baseline burden of annular pathology that is associated with progressive nuclear degeneration, it is possible that progressive disc degeneration also occurs in some patients despite their becoming asymptomatic. $^{22,24}$
Progressive degeneration was observed in stressed discs irrespective of bone healing on follow-up imaging. It implies that in some patients, longterm sequelae of high segmental spinal stresses may be left in the form of disc degeneration rather than a stress fracture (Fig 5). Studies in asymptomatic athletes have demonstrated a high prevalence of both bony stress reaction and disc degeneration in the lumbar spine, ${ }^{31,32}$ indicating that mechanical stress-induced bony fractures as well as accompanying disc degeneration can take place in the absence of overt pain. The role of mechanical factors in disc degeneration is well established. ${ }^{14,33-38}$ The previously reported higher burden of degeneration in stressed discs on both sides of the stressed vertebral segment ${ }^{14,18}$ suggests that in patients with a bony stress reaction, increased mechanical stresses are conveyed to the disc through the vertebral body to whichever disc components are attached. Whether, and to what extent, a similar mechanism may be responsible for initiating disc degeneration in the general population is unclear. Our results do suggest that in patients with advanced disc degeneration, intact posterior vertebral elements in the vertebrae around the degenerated disc do not exclude the possibility of a similar mechanism for the initiation of disc degeneration.

At baseline, the pattern of disc degeneration observed was similar to what has been previously reported, with a higher burden of annular fissures, radial fissures, and herniation as well as nuclear degeneration. ${ }^{14}$ Previous studies have highlighted the association between radial annular fissures and progressive nuclear degeneration. ${ }^{22,24,39-44}$ Therefore, it is to be expected that some stressed discs with annular pathology at baseline would undergo progressive nuclear degeneration on follow-up imaging irrespective of how the bony changes evolve, likely explaining the progressive disc degeneration in patients with improved bony stress reaction.

Although stressed discs showed a higher baseline burden of both annular and nuclear degeneration, progressive changes were mainly seen in the nucleus pulposus. Lack of a higher burden of new annular fissures in stressed discs could potentially be attributed to activity modifications induced by persistent symptoms in our patients. Alternatively, because the annulus may be the first component of the intervertebral discs to 


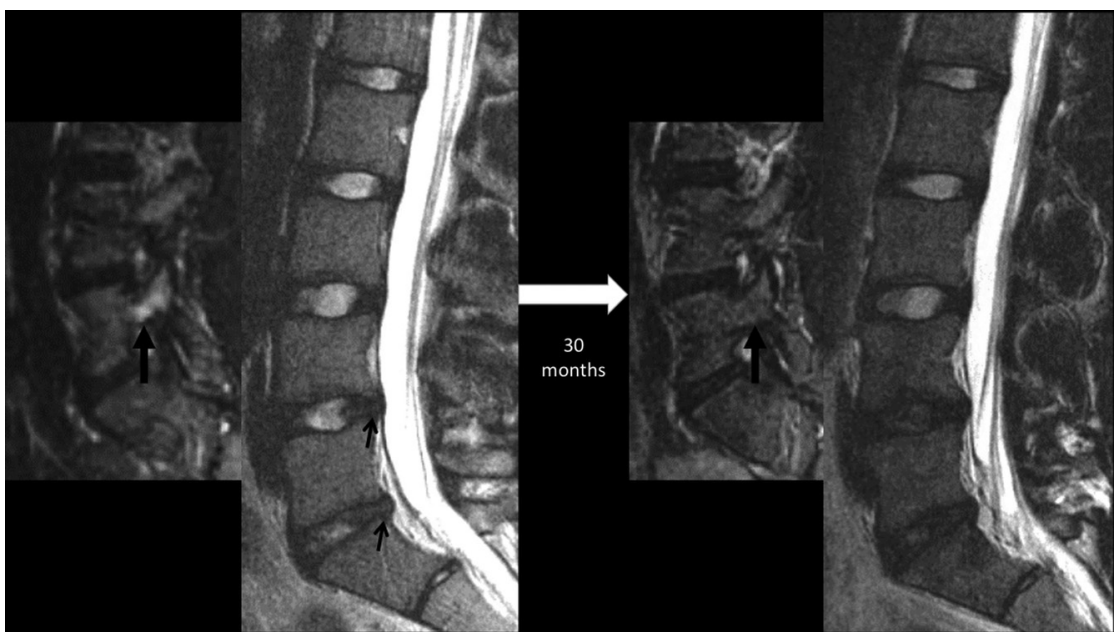

FIG 5. Sequential lumbar MR images obtained 30 months apart in a 15-year-old male patient with back pain, highlighting progressive disc degeneration despite the resolution of bony stress reaction. Initial MR imaging revealed edema in the right L5 pedicle (thick arrow) as shown here on a parasagittal STIR image, consistent with a stress reaction. Sagittal T2WI at this time revealed subtle annular fissures at the L4-5 and L5-S1 discs (small arrows) and signs of nuclear degeneration at the L5-S1 level. Follow-up MR imaging obtained 30 months later reveals the resolution of pedicular edema (thick arrow), but progressive loss of nuclear signal intensity of both stressed discs at the L4-5 and L5-S1 levels. Note that the control disc at the L3-4 level remains normal.

be affected in the degenerative process, ${ }^{14,22,24,25}$ it is possible that patients in whom the annulus was prone to stress-induced injury had already developed annular fissures by the time of presentation. A similar explanation could also be used to explain why only nuclear degeneration correlated with the bony stress grade. The Hollenberg grading system progressing from bony edema to fracture nonunion can be viewed as an indirect proxy for the duration and/or the degree of mechanical stresses. ${ }^{2}$ Accordingly, even the baseline imaging in these patients may provide a sense of the timeline of associated disc degeneration. Again, it is possible that any annulus fibrosus predisposed to rupture in the face of increased mechanical stresses did so early in the process, thereby inciting ongoing nuclear degeneration that became more evident as the disease progressed.

Stressed discs did not exhibit a higher burden of endplate defects. These results are concordant with those previously reported. ${ }^{14}$ Apparent discordance from other studies showing a strong association between Schmorl nodes and disc degeneration ${ }^{45}$ may simply reflect differences in the population being studied and the hypothesis being tested. Despite a strong correlation between endplate defects and nuclear degeneration, ${ }^{2,45}$ their segmental distributions differ. Endplate defects are more prevalent at the thoracolumbar junction with inherently weaker endplates, whereas nuclear degeneration preferentially affects caudal segments of the lumbar spine. ${ }^{14,22,45-47}$ Stressed discs in our study were mainly seen in the caudal half of the lumbar spine, likely explaining a low burden of endplate defects in both stressed and control discs.

The retrospective nature of our study imposes some limitations. Very few segments from the upper lumbar spine were represented in our study. We did not take into consideration the weight of patients or activity level between the 2 studies. Although both of these factors can influence the risk of disc degeneration, these factors would have affected both the stressed and control discs. A longer follow-up duration could have further exaggerated the differences in the progression of disc degeneration of stressed versus control discs. Similarly, the overall burden of disc degeneration could have been different had we restricted the study to higher-strength MR imaging. Despite these limitations, the selection of stressed and control discs from the same patients allowed us to conclusively demonstrate a higher burden of both the baseline and the progressive degeneration of discs in lumbar spinal segments experiencing higher mechanical stress.

\section{CONCLUSIONS}

Intervertebral discs in stressed segments of the lumbar spine demonstrate a higher burden of disc degeneration at baseline and an increased risk of progressive degeneration irrespective of the outcome of bony changes. The progression of disc degeneration occurs mainly in the form of worsening nuclear degeneration.

\section{REFERENCES}

1. Dunn AJ, Campbell RS, Mayor PE, et al. Radiological findings and healing patterns of incomplete stress fractures of the pars interarticularis. Skeletal Radiol 2008;37:443-50 CrossRef Medline

2. Hollenberg GM, Beattie PF, Meyers SP, et al. Stress reactions of the lumbar pars interarticularis: the development of a new MRI classification system. Spine (Phila Pa 1976) 2002;27:181-86 CrossRef Medline

3. Motley G, Nyland J, Jacobs J, et al. The pars interarticularis stress reaction, spondylolysis, and spondylolisthesis progression. J Athl Train 1998;33:351-58 Medline

4. Pennell RG, Maurer AH, Bonakdarpour A. Stress injuries of the pars interarticularis: radiologic classification and indications for scintigraphy. AJR Am J Roentgenol 1985;145:763-66 CrossRef Medline

5. Tofte JN, CarlLee TL, Holte AJ, et al. Imaging pediatric spondylolysis: a systematic review. Spine (Phila Pa 1976) 2017;42: 777-82 CrossRef Medline

6. Nitta A, Sakai T, Goda Y, et al. Prevalence of symptomatic lumbar spondylolysis in pediatric patients. Orthopedics 2016;39:e434-37 CrossRef Medline

7. Changstrom BG, Brou L, Khodaee M, et al. Epidemiology of stress fracture injuries among US high school athletes, 2005-2006 through 2012-2013. Am J Sports Med 2015;43:26-33 CrossRef Medline

8. Bouras T, Korovessis P. Management of spondylolysis and lowgrade spondylolisthesis in fine athletes. A comprehensive review. Eur J Orthop Surg Traumatol 2015;25(suppl 1):S167-75 CrossRef Medline

9. Mora-de Sambricio A, Garrido-Stratenwerth E. Spondylolysis and spondylolisthesis in children and adolescents [in Spanish]. Rev Esp Cir Ortop Traumatol 2014;58:395-406 CrossRef Medline

10. Donaldson LD. Spondylolysis in elite junior-level ice hockey players. Sports Health 2014;6:356-59 CrossRef Medline

11. Barrack MT, Gibbs JC, De Souza MJ, et al. Higher incidence of bone stress injuries with increasing female athlete triad-related risk 
factors: a prospective multisite study of exercising girls and women. Am J Sports Med 2014;42:949-58 CrossRef Medline

12. Morita T, Ikata T, Katoh S, et al. Lumbar spondylolysis in children and adolescents. J Bone Joint Surg Br 1995;77:620-25 Medline

13. Papanicolaou N, Wilkinson RH, Emans JB, et al. Bone scintigraphy and radiography in young athletes with low back pain. AJR Am J Roentgenol 1985;145:1039-44 CrossRef Medline

14. Sharma A, Lancaster S, Bagade S, et al. Early pattern of degenerative changes in individual components of intervertebral discs in stressed and nonstressed segments of lumbar spine: an in vivo magnetic resonance imaging study. Spine (Phila Pa 1976) 2014;39: 1084-90 CrossRef Medline

15. Iwamoto J, Sato Y, Takeda T, et al. Return to sports activity by athletes after treatment of spondylolysis. World J Orthop 2010;1:26-30 CrossRef Medline

16. Pizzutillo PD, Hummer CD 3rd. Nonoperative treatment for painful adolescent spondylolysis or spondylolisthesis. J Pediatr Orthop 1989;9:538-40 CrossRef Medline

17. Modic MT, Ross JS. Lumbar degenerative disk disease. Radiology 2007;245:43-61 CrossRef Medline

18. Jeong HY, You JW, Sohn HM, et al. Radiologic evaluation of degeneration in isthmic and degenerative spondylolisthesis. Asian Spine J 2013;7:25-33 CrossRef Medline

19. Dai LY. Disc degeneration in patients with lumbar spondylolysis. J Spinal Disord 2000;13:478-86 CrossRef Medline

20. Szypryt EP, Twining P, Mulholland RC, et al. The prevalence of disc degeneration associated with neural arch defects of the lumbar spine assessed by magnetic resonance imaging. Spine (Phila $\mathrm{Pa}$ 1976) 1989;14:977-81 CrossRef Medline

21. Schlenzka D, Poussa M, Seitsalo S, et al. Intervertebral disc changes in adolescents with isthmic spondylolisthesis. J Spinal Disord 1991; 4:344-52 CrossRef Medline

22. Sharma A, Parsons M, Pilgram T. Temporal interactions of degenerative changes in individual components of the lumbar intervertebral discs: a sequential magnetic resonance imaging study in patients less than $\mathbf{4 0}$ years of age. Spine (Phila Pa 1976) 2011;36: 1794-800 CrossRef Medline

23. Pfirrmann CW, Metzdorf A, Zanetti M, et al. Magnetic resonance classification of lumbar intervertebral disc degeneration. Spine (Phila Pa 1976) 2001;26:1873-78 CrossRef Medline

24. Sharma A, Pilgram T, Wippold FJ 2nd. Association between annular tears and disk degeneration: a longitudinal study. AJNR Am J Neuroradiol 2009;30:500-06 CrossRef Medline

25. Sharma A, Parsons MS, Pilgram TK. Temporal association of annular tears and nuclear degeneration: lessons from the pediatric population. AJNR Am J Neuroradiol 2009;30:1541-45 CrossRef Medline

26. Paajanen $\mathrm{H}$, Tertti M. Association of incipient disc degeneration and instability in spondylolisthesis. A magnetic resonance and flexion-extension radiographic study of 20-year-old low back pain patients. Arch Orthop Trauma Surg 1991;111:16-19 CrossRef Medline

27. Lee GW, Lee SM, Ahn MW, et al. Comparison of surgical treatment with direct repair versus conservative treatment in young patients with spondylolysis: a prospective, comparative, clinical trial. Spine J 2015;15:1545-53 CrossRef Medline

28. Menga EN, Kebaish KM, Jain A, et al. Clinical results and functional outcomes after direct intralaminar screw repair of spondylolysis. Spine 2014;39:104-10 CrossRef Medline

29. Mohriak R, Vargas Silva PD, Trandafilov M, Jr., et al. Spondylolysis and spondylolisthesis in young gymnasts. Rev Bras Ortop 2010;45: 79-83 CrossRef Medline

30. Scheepers MS, Streak Gomersall J, Munn Z. The effectiveness of surgical versus conservative treatment for symptomatic unilateral spondylolysis of the lumbar spine in athletes: a systematic review.
JBI Database System Rev Implement Rep 2015;13:137-73 CrossRef Medline

31. Rajeswaran G, Turner M, Gissane C, et al. MRI findings in the lumbar spines of asymptomatic elite junior tennis players. Skeletal Radiol 2014;43:925-32 CrossRef Medline

32. Alyas F, Turner M, Connell D. MRI findings in the lumbar spines of asymptomatic, adolescent, elite tennis players. Br J Sports Med 2007; 41:836-41; discussion 841 CrossRef Medline

33. Rajasekaran S, Vidyadhara S, Subbiah M, et al. ISSLS prize winner: a study of effects of in vivo mechanical forces on human lumbar discs with scoliotic disc as a biological model: results from serial postcontrast diffusion studies, histopathology and biochemical analysis of twenty-one human lumbar scoliotic discs. Spine (Phila Pa 1976) 2010;35:1930-43 CrossRef Medline

34. Ariga K, Yonenobu K, Nakase T, et al. Mechanical stress-induced apoptosis of endplate chondrocytes in organ-cultured mouse intervertebral discs: an ex vivo study. Spine (Phila Pa 1976) 2003;28: 1528-33 CrossRef Medline

35. Adams MA, Freeman BJ, Morrison HP, et al. Mechanical initiation of intervertebral disc degeneration. Spine (Phila Pa 1976) 2000;25: 1625-36 CrossRef Medline

36. Lotz JC, Colliou OK, Chin JR, et al. Compression-induced degeneration of the intervertebral disc: an in vivo mouse model and finiteelement study. Spine 1998;23:2493-506 CrossRef Medline

37. Natarajan RN, Ke JH, Andersson GB. A model to study the disc degeneration process. Spine (Phila Pa 1976) 1994;19:259-65 CrossRef Medline

38. Adams MA, Hutton WC. Prolapsed intervertebral disc. A hyperflexion injury 1981 Volvo Award in Basic Science. Spine 1982;7:184-91 CrossRef Medline

39. Moore RJ, Latham JM, Vernon-Roberts B, et al. Does plate fixation prevent disc degeneration after a lateral anulus tear? Spine 1994;19: 2787-90 CrossRef Medline

40. Osti OL, Vernon-Roberts B, Fraser RD. 1990 Volvo Award in experimental studies. Anulus tears and intervertebral disc degeneration. An experimental study using an animal model. Spine (Phila Pa 1976) 1990;15:762-67 CrossRef Medline

41. Yu SW, Sether LA, Ho PS, et al. Tears of the anulus fibrosus: correlation between MR and pathologic findings in cadavers. AJNR AmJ Neuroradiol 1988;9:367-70 Medline

42. Milette PC, Fontaine S, Lepanto L, et al. Differentiating lumbar disc protrusions, disc bulges, and discs with normal contour but abnormal signal intensity. Magnetic resonance imaging with discographic correlations. Spine (Phila Pa 1976) 1999;24:44-53 CrossRef Medline

43. Olsewski JM, Schendel MJ, Wallace LJ, et al. Magnetic resonance imaging and biological changes in injured intervertebral discs under normal and increased mechanical demands. Spine (Phila Pa 1976) 1996;21:1945-51 CrossRef Medline

44. Dullerud R, Johansen JG. CT-diskography in patients with sciatica Comparison with plain CT and MR imaging. Acta Radiol 1995;36: 497-504 CrossRef Medline

45. Mok FP, Samartzis D, Karppinen J, et al. ISSLS prize winner: prevalence, determinants, and association of Schmorl nodes of the lumbar spine with disc degeneration: a population-based study of 2449 individuals. Spine (Phila Pa 1976) 2010;35:1944-52 CrossRef Medline

46. Hou Y, Luo Z. A study on the structural properties of the lumbar endplate: histological structure, the effect of bone density, and spinal level. Spine (Phila Pa 1976) 2009;34:E427-33 CrossRef Medline

47. Miller JA, Schmatz C, Schultz AB. Lumbar disc degeneration: correlation with age, sex, and spine level in $\mathbf{6 0 0}$ autopsy specimens. Spine (Phila Pa 1976) 1988;13:173-78 CrossRef Medline 